\title{
Defected Ground Structure toward Cross Polarization Reduction of Microstrip Patch Antenna with Improved Impedance Matching
}

\author{
Juin ACHARJEE ${ }^{1}$, Amit Kumar SINGH' ${ }^{2}$ Kaushik MANDAL ${ }^{3}$, Sujit Kumar MANDAL ${ }^{4}$ \\ ${ }^{1}$ Dept. of Electronics \& Communication Eng., St. Thomas' College of Engineering \& Technology, 700023, Kolkata, India \\ ${ }^{2}$ Dept. of Electronics \& Communication Engineering, NSHM Knowledge Campus Durgapur, 713212, India \\ ${ }^{3}$ Inst. of Radio Physics and Electronics, University of Calcutta, Kolkata, 700009, India \\ ${ }^{4}$ Dept. of Electronics and Communication Engineering, NIT Durgapur, 713209, India
}

juin.ece@gmail.com

Submitted August 7, 2018 / Accepted December 13, 2018

\begin{abstract}
A new approach based on the incorporation of Zshaped defected ground structure (DGS) in microstrip antenna (MSA) for improving impedance matching and cross polarization (XP) performances is proposed in this paper. Through detail analysis of the surface current densities, and input impedance, the proposed DGS is integrated into a rectangular MSA (RMSA) to realize flat relative $X P$ reduction of $22 \mathrm{~dB}$ in the $H$-plane around broadside angular range of $\pm 60^{\circ}$. Further, an equivalent circuit model (ECM) for the proposed antenna is introduced by considering the mutual coupling in between the DGS and patch and the model is verified using circuit-system-EM cosimulation software, Advanced Design System (ADS). A prototype has been fabricated and tested for the validation of simulated results and it shows good agreement with each other. The antenna operates over 2.32-2.58 GHz with good far-field radiation characteristics and a peak gain of $2.8 \mathrm{dBi}$ at the resonating frequency $2.4 \mathrm{GHz}$. Hence, the proposed design can be useful for the IEEE $802.11 \mathrm{~b}$ applications.
\end{abstract}

\section{Keywords}

Impedance matching, cross-polarization, defected ground structure, microstrip patch antenna, equivalent circuit

\section{Introduction}

In the past decades microstrip antennas (MSA) have received much attention and have been intensively studied because of their low cost, lightweight, and low profile. However, MSA commonly sustain high input impedance, typically in a range of $300-500 \Omega$, which is difficult for proper matching with $50-\Omega$ SMA connector for the coaxial probe feed. The input impedance of a MSA depends on its shape, dimensions, properties of the materials, and the feed type. The experimental investigation [1] has shown that the dependence of the input resistance on the feed position differs in case of a simple coaxial probe feed and a microstrip line feed. Generally the input impedance of the probe feed MSA is proportional to the cosine squared of the normalized feed point distance with respect to the patch edge but for the inset microstrip line feed, the impedance dependence becomes proportional to the fourth power of the cosine [2]. For the probe feed at the center of the patch, the input impedance is zero. The input impedance behavior of the inset-fed rectangular MSA [3] depends on the notch width and the aspect ratio of the patch. It also shows that XP level in H-plane increases by increasing either the notch width or depth. However, for fixed input impedance, the cross-polarization level is not very sensitive to the notch width. Recently, a new technique using a pair of shorting pins [4] has been explored toward the flexible impedance matching and lower XP level of a rectangular MSA. Due to the symmetric arrangement of shorting pins, surface current density on the patch is maintained as the odd-symmetric property with respect to the H-plane, thus the XP level is reduced significantly.

Proper input impedance matching of MSA plays an important role towards the improvement of the impedance bandwidth. The bandwidth enhancement of a MSA by employing a Z- shaped DGS for X-band application is reported in [5] nevertheless, incorporation of DGS for improving input impedance matching has not been explored. Defected ground plane is also used to enhance the bandwidth of an ultrawideband antenna [6] along with XP suppression. Though XP level improves by $12-22 \mathrm{~dB}$ in both the principal planes however, after inserting the DGS impedance matching deteriorates.

Apart from many desirable properties, a simple rectangular MSA suffers from XP radiation in the far field, especially in the H-plane. The asymmetry of the probe location results in asymmetry in the near fields in the vicinity of the antenna, causing high XP radiation in the $\mathrm{H}$ plane of the antenna. XP reduction using symmetric arcshaped DGS [7], asymmetric DGS [8], a strategic design of 
DGS [9], and a dumbbell shaped DGS, without affecting co-polarized radiation pattern [10] have been explored to understand the effectiveness of DGSs towards this issue. It has been found that the XP reduction along with proper impedance matching is a difficult task for the MSA designers. Because, for the proper impedance matching there is the requirement of asymmetric feed location which is also responsible for the higher XP radiation in the H-plane. Moreover, XP suppression in the boresight is not a difficult task but it is difficult to achieve very low and flat XP over the wide angle $\left(-60^{\circ}\right.$ to $\left.+60^{\circ}\right)$.

In this paper, a coaxial probe feed RMSA with Z-shaped DGS is proposed and analyzed for improved impedance matching and XP performances. The position of the DGS is optimized to get desired $\mathrm{x}$-directed odd-symmetric surface current distribution so that the corresponding radiated far field can be cancelled each other in the H-plane. Considering the mutual coupling in between the patch and DGS an ECM is developed and verified using circuit-system-EM-co-simulation software, Advanced Design System (ADS-2017). Improved impedance matching over 2.32-2.58 GHz, low and flat XP level over the entire tracking angle $-60^{\circ}$ to $+60^{\circ}$, and good far-field radiation along with reasonable peak gain of $2.8 \mathrm{dBi}$ make this antenna suitable for the IEEE $802.11 \mathrm{~b}$ applications. The antenna design is carried out using FEM-based Ansys HFSS EM simulator.

\section{Antenna Design}

In this section configuration of the proposed antenna and its equivalent circuit model have been discussed.

\subsection{Antenna Configuration}

The detailed of the antenna structure is shown in Fig. 1. An easily available FR4 substrate of dimension $38 \mathrm{~mm} \times 47 \mathrm{~mm}$ with dielectric constant $\left(\varepsilon_{\mathrm{r}}\right) 4.4$ and thickness $(h) 1.6 \mathrm{~mm}$ is used for the antenna design. A rectangular shaped patch is printed on one side of the substrate with dimension $25.98 \mathrm{~mm} \times 29.79 \mathrm{~mm}$. The resonance frequency $(2.4 \mathrm{GHz})$ for the dominant $\mathrm{TM}_{10}$ mode of RMSA can be calculated by the following formula [9]

$$
f \approx \frac{c_{0}}{0.89(L+W) \sqrt{\varepsilon_{\mathrm{r}}}}
$$

where, $c_{0} \mathrm{c}_{0}$ is the velocity of light, $L$ and $W$ are the length and width of the patch respectively.

One Z-shaped metal of length $0.16 \lambda_{0}$ from the upper middle portion of the ground plane has been etched to create a groove (DGS) on the ground plane, where $\lambda_{0}$ is the free space wavelength corresponding to the resonating frequency. Due to the insertion of the DGS the pass band and stop band is modified and therefore antenna shows new resonating behavior. Co-axial probe feeding technique is used to feed the antenna structure. All the dimensions of the antenna parameters are given in Tab. 1.
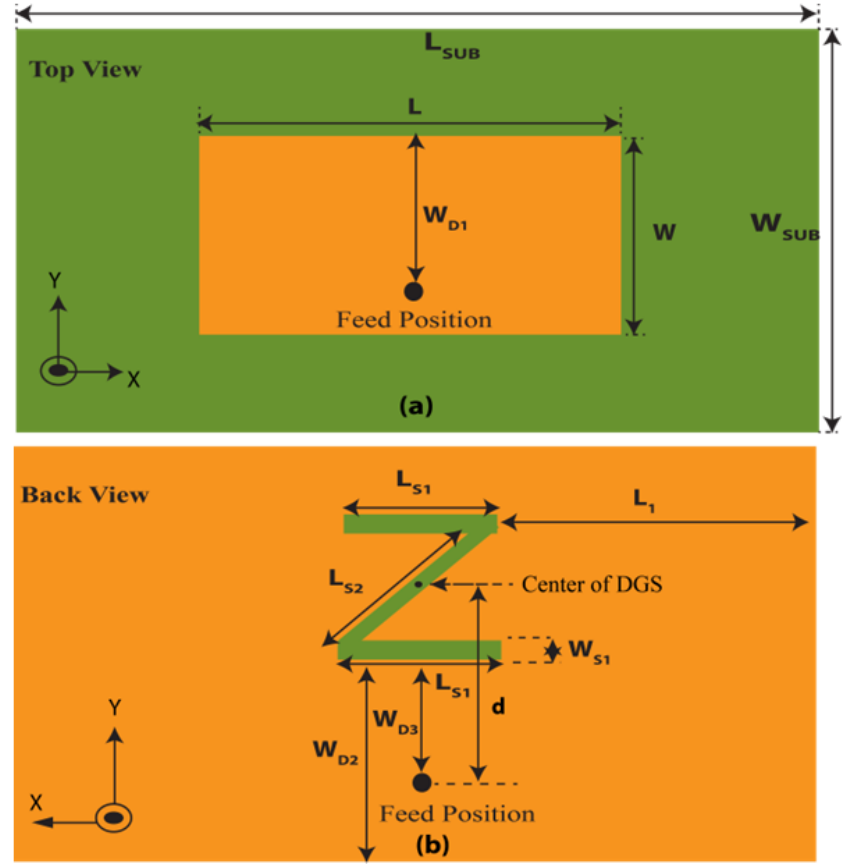

Fig. 1. Detailed diagram of the proposed Z-shaped DGS integrated RMSA: (a) Top view. (b) Back view.

\begin{tabular}{|c|c|c|c|c|c|}
\hline $\mathbf{W}$ & $\mathbf{L}$ & $\mathbf{L}_{\text {SUB }}$ & $\mathbf{W}_{\text {SUB }}$ & $\mathbf{L}_{\mathbf{S 1}}$ & $\mathbf{L}_{\mathbf{S} 2}$ \\
\hline 28.5 & 38.1 & 47.7 & 38.1 & 6 & 7.8 \\
\hline $\mathbf{W}_{\mathbf{D} 1}$ & $\mathbf{W}_{\mathbf{D} 2}$ & $\mathbf{W}_{\mathbf{D} 3}$ & $\mathbf{W}_{\mathbf{S} 1}$ & $\mathbf{L}_{1}$ & $\mathbf{d}$ \\
\hline 18.5 & 25.5 & 13.7 & 1 & 15 & 17.7 \\
\hline
\end{tabular}

Tab. 1. Proposed antenna design parameters with optimized values (All dimensions are in $\mathrm{mm}$ ).

\subsection{Equivalent Circuit Model (ECM)}

The equivalent circuit of the co-axial probe feed RMSA loaded with Z-shaped DGS is shown in Fig. 2, where the effect of the Z-shaped slot is introduced by considering mutual inductance between the DGS and patch. The input side consisting of parallel capacitance $C_{\mathrm{p}}$, inductance $L_{\mathrm{p}}$, and resistance $R_{\mathrm{p}}$ signifies the equivalent circuit of the MSA. As DGS structure is included in the ground plane, a parallel $\mathrm{LC}$ circuit ( $L_{\mathrm{DGS}}$ and $C_{\mathrm{DGS}}$ ) corresponding to the DGS is mutually connected with the patch antenna.

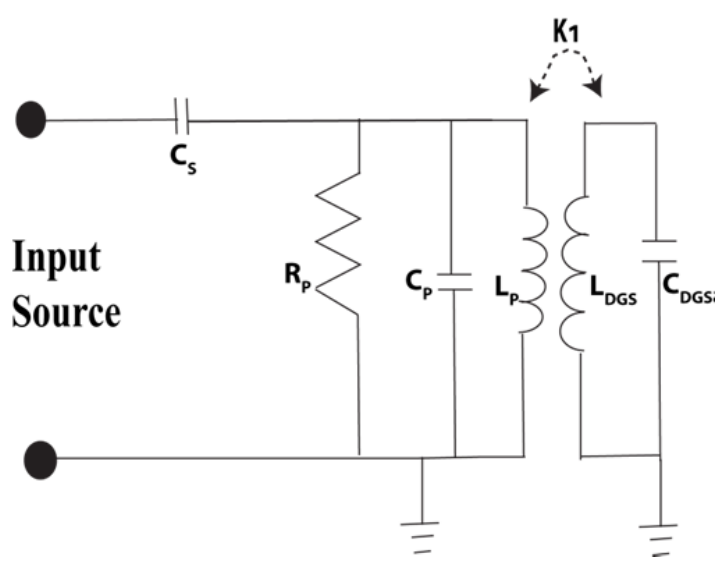

Fig. 2. Equivalent circuit of the DGS integrated antenna. 
The following equations are used for parameter extraction of equivalent circuit components of the DGS section and patch section [11], [12].

$$
\begin{gathered}
C_{\mathrm{S}}=\frac{\tan (\beta s)}{\omega_{0} Z_{0}}, \\
C_{\mathrm{P}}=\frac{\varepsilon_{0} \varepsilon_{\mathrm{e}} L W}{2 h} \cos ^{-2}\left(\frac{\pi y_{0}}{L}\right), \\
R_{\mathrm{P}}=\frac{Q}{\omega C_{\mathrm{P}}}, \\
Q=\frac{c_{0} \sqrt{\varepsilon_{\mathrm{e}}}}{4 f_{0} h}, \\
L_{\mathrm{P}}=\frac{1}{4 \pi^{2} f_{0}^{2} C_{\mathrm{P}}}, \\
C_{\mathrm{DGS}}=\frac{\omega_{\mathrm{c}}}{2 Z_{0}\left(\omega_{0}^{2}-\omega_{\mathrm{c}}^{2}\right)}, \\
L_{\mathrm{DGS}}=\frac{1}{4 \pi^{2} f_{0}^{2} C_{\mathrm{DGS}}}, \\
f_{0}=\frac{1}{2 \pi \sqrt{L_{\mathrm{DGS}} C_{\mathrm{DGS}}}}
\end{gathered}
$$

where $\beta$ is the wave number, $s$ is the stub length, $C_{\mathrm{S}}$ is the source capacitance, $Z_{0}$ is the characteristics impedance, $h$ is the substrate thickness, $C_{\mathrm{DGS}}$ and $L_{\mathrm{DGS}}$ are the capacitance and inductance value of the equivalent circuit of the DGS section, $y_{\mathrm{o}}$ is the distance of the feed point from the patch edge, $\omega_{0}$ is the resonating angular frequency and $\omega_{\mathrm{c}}$ is the 3-dB lower cut-off angular frequency. The coupling coefficient $\left(K_{1}\right)$ between the inductors is obtained as 0.04 according to the following formula as given in (10) and as detailed in [13].

$$
K_{1}=\frac{f_{\mathrm{e}}^{2}-f_{\mathrm{m}}^{2}}{f_{\mathrm{e}}^{2}+f_{\mathrm{m}}^{2}}
$$

where $f_{\mathrm{e}}$ and $f_{\mathrm{m}}$ are the frequencies corresponding to the lower and upper 3-dB points around the resonance frequency and these positions are known as electric and magnetic walls respectively. Substituting the values of all the known parameters to (2)-(10), the calculated values of all the unknown parameters are $C_{\mathrm{S}}=20.9 \mathrm{pF}, R_{\mathrm{P}}=49 \Omega$, $L_{\mathrm{P}}=0.468 \mathrm{nH}, L_{\mathrm{DGS}}=1.87 \mathrm{nH}$, and $C_{\mathrm{DGS}}=2.35 \mathrm{pF}$, considering $f_{\mathrm{e}}$ and $f_{\mathrm{m}}$ as $2.35 \mathrm{GHz}$ and $2.45 \mathrm{GHz}$ respectively. These circuit parameters have been used to design the circuit model of Fig. 2 using ADS-2017. The response of this ECM is compared with the simulated and measured reflection coefficients $\left(S_{11}\right)$, as illustrated in Fig. 7 of Sec. 3.3.

Since, due to the mutual coupling effect in between the patch and DGS, the equivalent input impedance of the antenna changes which leads to alter the current distributions on the ground plane. This variation in current distribution alters the fringing field effect which leads to modify the effective dielectric constant. Now according to (5) this effective dielectric constant is directly proportioned to the square of the quality factor $(Q)$. Further, the bandwidth $(B W)$ of the antenna is inversely proportional to the quality factor following the relation $B W=(V S W R-1) / Q \sqrt{V S W R}$.

So, change in effective dielectric constant due to DGS incorporation will affect the quality factor and the bandwidth of the antenna accordingly.

\section{Results and Discussion}

\subsection{Input Impedance}

The simulated input resistance $\left(R_{\text {in }}\right)$ and reactance $\left(X_{\text {in }}\right)$ variations with different locations of the DGS are summarized in Fig. 3. Left and right shift of the DGS from its proposed position has been defined in terms of the ratio of the diagonal spacing $\left(d_{1}\right.$ and $\left.d_{2}\right)$ between the center of the DGS and feed point to the substrate width $W_{\text {SUB }}$. The parameters $d, d_{1}$, and $d_{2}$ are defined in the inset of Fig. 3(b). As the value of $W_{\text {SUB }}(38.1 \mathrm{~mm})$ and the ratios are known then following the inset of Fig. 3(b), one can calculate the value of the variables $d_{1}, d_{2}, X_{1}$, and $X_{2}$. For the proposed position of the DGS $\left(d / \mathrm{W}_{\mathrm{SUB}}=0.6\right), R_{\text {in }}$ attains a maximum value of $57 \Omega$ and $X_{\text {in }}=0$ at the resonance frequency $2.4 \mathrm{GHz}$, whereas for other positions of the DGS the resonance frequency has been changed. The real values of the input resistance followed the Gaussian distribution whereas for its imaginary part a shifted cosine distribution has been observed which indicates the purity of the dominant mode generation.

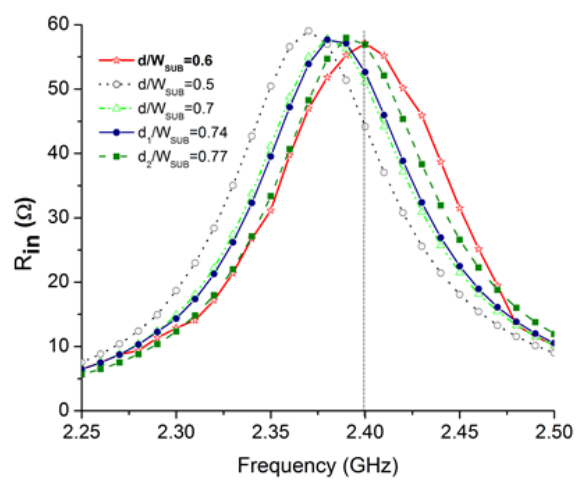

(a)

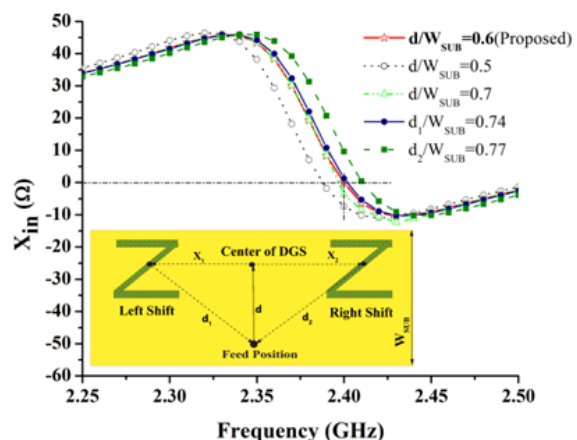

(b)

Fig. 3. (a) Input resistance $\left(R_{\text {in }}\right)$ and (b) reactance $\left(X_{\text {in }}\right)$ of the DGS loaded antenna for different position of DGS on the ground plane. 


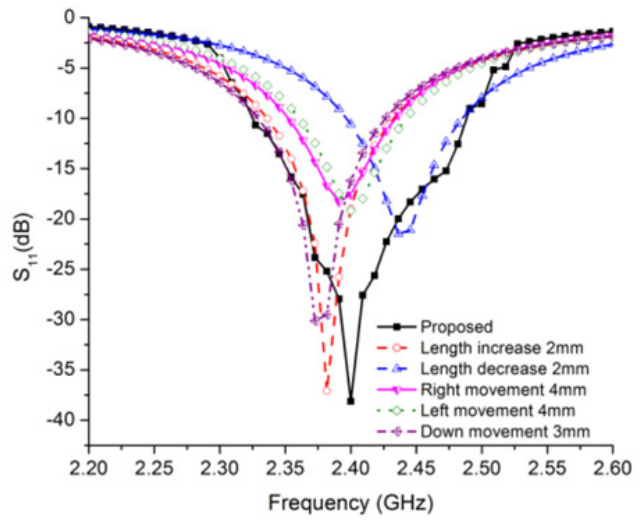

Fig. 4. Variation in simulated reflection coefficient for size and position variation of the DGS.

To establish a strong evidence for the suitability of the proposed DGS size and position, simulated reflection coefficients under different circumstances are shown in Fig. 4. This study reveals that for the increment and decrement of the DGS size with respect to the proposed size the resonating frequency has been decreased and increased respectively but the impedance matching is affected only when the DGS length is decreased. However, for the right and left shift of the DGS position with respect to the proposed position the reflection coefficient exhibits poor impedance matching at the resonating frequency. Hence, the position of the DGS plays the most important role towards the better impedance matching issue.

\subsection{Surface Current Distribution and XP Performance}

Surface current vectors on the patch for various positions of the DGS are illustrated in Fig. 5. Due to the incorporation of DGS the surface current is perturbed and the position of the DGS is optimized to produce odd symmetric for the XP reduction. Apart from the proposed DGS position, there is no evidence of the odd-symmetric $\mathrm{X}$-oriented surface current vectors generated from the co-axial probe with respect to the H-plane; hence the corresponding radiated fields will not cancel each other, which lead to the problem of higher XP in H-plane for the other positions of DGS as shown in Fig. 6.

Therefore the proposed centered position of the DGS is justified in terms of surface current vectors and lower XP performance. It has been observed that there is no effect on the co-pol patterns due to DGS position variation however cross-pol patterns in the H-plane changes significantly. Due to the proper cancellation of radiated fields for the proposed position of Z-shaped DGS, it exhibits flat XP pattern in the H-plane with a relative $\mathrm{XP}$ reduction of $22 \mathrm{~dB}$ around $\pm 60^{\circ}$ with respect to the other positions of DGS.

\subsection{Measured Results}

To validate the antenna performance a prototype has been fabricated and the reflection coefficient and radiation patterns are measured using proper experimental setup.

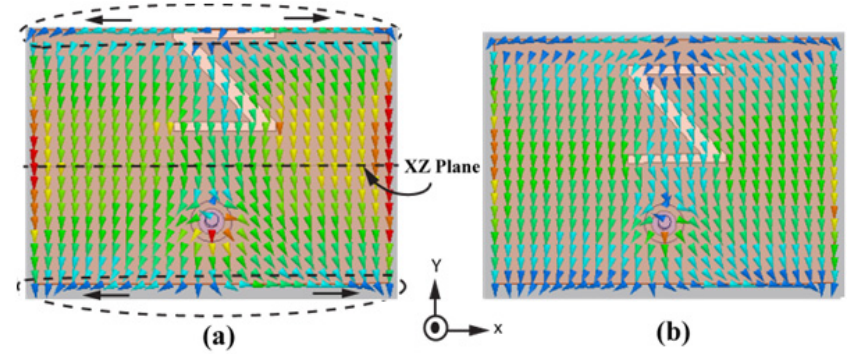

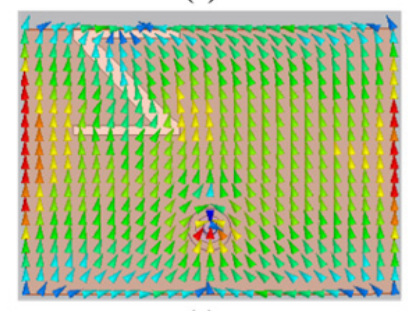

(c)

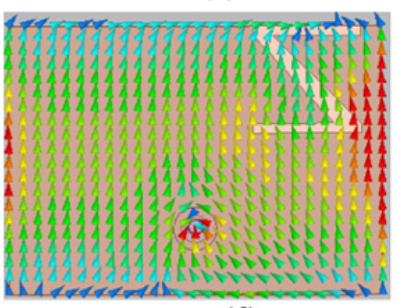

(d)
Fig. 5. Surface current vectors distribution on the patch with different DGS positions: (a) proposed, (b) down shift, (c) left shift, (d) right shift.

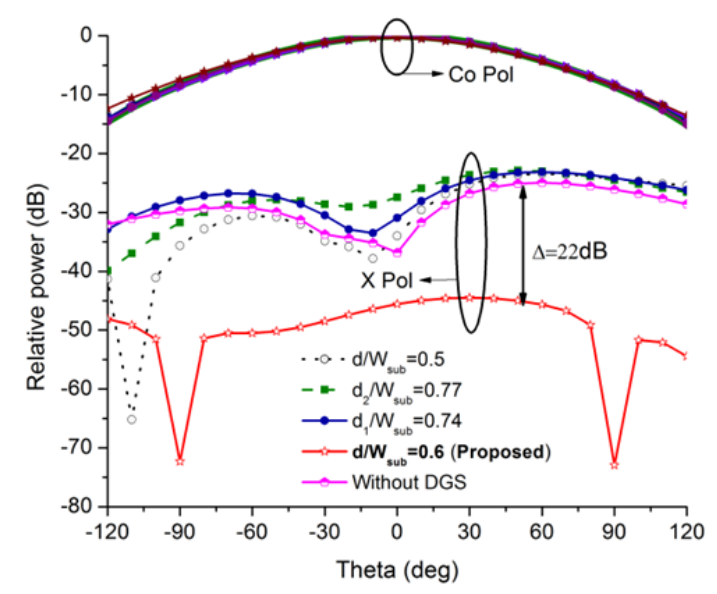

Fig. 6. Co-pol patterns for both E-plane and H-plane and the $\mathrm{x}$-pol patterns only for the H-plane.

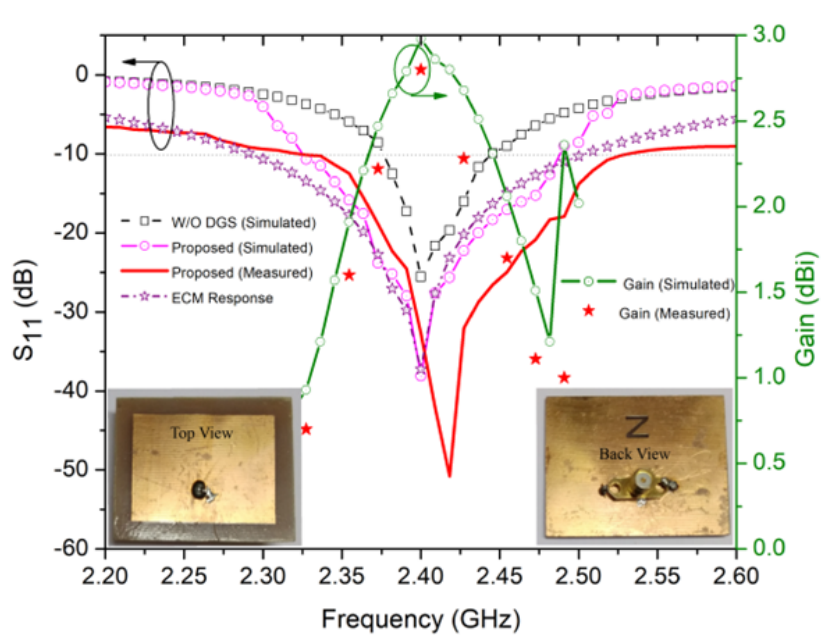

Fig. 7. $S_{11}$ vs frequency characteristics, and gain vs frequency characteristic.

A comparative study of reflection coefficients without DGS, with DGS, simulated and measured is summarized in Fig. 7. This figure also shows the simulated and measured 


\begin{tabular}{|c|c|c|c|c|c|}
\hline Ref. no. & Methodology used & $\begin{array}{l}\text { Size of the patch } \\
\left(\mathrm{mm}^{2}\right)\end{array}$ & $\begin{array}{l}\text { Operating band } \\
(\mathrm{GHz})\end{array}$ & $\begin{array}{l}\mathrm{XP} \text { reduction } \\
\quad(\mathrm{dB})\end{array}$ & $\begin{array}{l}\text { Impedance matching } \\
\text { improvements }\end{array}$ \\
\hline [4] & Pair of shorting pins & $0.3 \lambda_{0} \times 0.3 \lambda_{0}$ & around $2.241 \& 2.478$ & 16 & $\begin{array}{c}\text { Flexible matching } \\
\text { (values are not mentioned) }\end{array}$ \\
\hline [6] & $\begin{array}{l}\text { Combination of DGS } \\
\text { and slotted patch }\end{array}$ & $0.2 \lambda_{0} \times 0.23 \lambda_{0}$ & $2-21$ & $\begin{array}{l}\text { XP increased in the E- } \\
\text { plane but in the H-plane } \\
\text { XP reduced by } 20 \mathrm{~dB}\end{array}$ & $\begin{array}{c}\text { After inserting DGS } \\
\text { impedance matching } \\
\text { deteriorates }\end{array}$ \\
\hline [7] & DGS & $1.0 \lambda_{0} \times 1.0 \lambda_{0}$ & $5.83-6.03$ & $7-12$ & $5 \mathrm{~dB}$ (approx) \\
\hline [8] & Asymmetric DGS & $2 \lambda_{0} \times 2 \lambda_{0}$ & $\begin{array}{l}9.5-10.4 \\
\text { (approx.) }\end{array}$ & 15 & Not mentioned \\
\hline Proposed & Z-shaped DGS & $0.3 \lambda_{0} \times 0.37 \lambda_{0}$ & $2.32-2.58$ & 22 & $26 \mathrm{~dB}$ \\
\hline
\end{tabular}

Tab. 2. Performance comparison of the proposed structure.

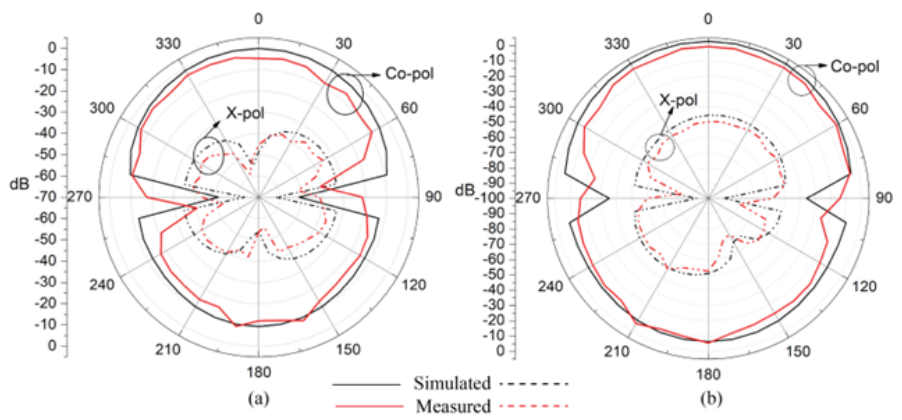

Fig. 8. Simulated and measured radiation patterns of the proposed antenna at $2.4 \mathrm{GHz}$ (a) E-plane, (b) H-plane.

gain variation throughout the operating frequency range. It can be concluded that with the introduction of the DGS the operational band changes from $2.35-2.46 \mathrm{GHz}$ to 2.32-2.58 GHz and impedance matching is improved from $-30 \mathrm{~dB}\left(\mathrm{~S}_{11} \mathrm{~W} / \mathrm{O} \mathrm{DGS}\right)$ to $-50 \mathrm{~dB}\left(\mathrm{~S}_{11}\right.$ with DGS). A good similarity is also observed between the simulated result and response of ECM model. Over the entire operating band, the gain is in the acceptable range and it shows a maximum peak gain of $2.8 \mathrm{dBi}$ at the resonating frequency. In this analysis, the bandwidth improvement using Z-shaped DGS is about $150 \mathrm{MHz}$. This amount of bandwidth improvement is not sufficient for many applications but this analysis can be applied to any shape of the DGS to improve the impedance matching as well as for the bandwidth enhancement of an MSA.

Stable radiation patterns at the resonating frequency in both principal planes are shown in Fig. 8. For both planes lower XP level is achieved. To enlighten the advantages of the proposed technique over the previously proposed techniques, a comparative study is carried out and summarized in Tab. 2. Critical analysis of Tab. 2 shows that the proposed design is very simple and able to achieve higher level of XP reduction along with better impedance matching.

\section{Conclusion}

The applicability of the DGS toward better impedance matching as well as XP level suppression has been explored successfully. Size and position of the DGS are cru- cial to achieving desired input impedance and current distributions. Centered position of the DGS provides the best result in terms of impedance matching and XP reduction. An analysis is carried out to identify the particular location with maximum surface current density beneath the patch. The position of the DGS has been fixed accordingly to improve the impedance matching. Improved impedance matching along with low and flat XP level throughout the entire tracking angle $-60^{\circ}$ to $+60^{\circ}$, make this work promising in comparison to the related works of its class. The proposed ECM also provides the better insight of the design and it will be helpful for the antenna community. This study opens a new avenue to find out the optimum position of DGS for the maximum impedance matching and XP suppressions.

\section{Acknowledgment}

This work is financially supported by the Ministry of Electronics and Information Technology (MeitY), Govt. of India under Visvesvaraya Young Faculty Fellowship $\mathrm{PhD}$ scheme (Grant No. PhD-MLA-4(29)/2015-16).

\section{References}

[1] BASILIO, L. I., KHAYAT, M. A., JEFFERY T. WILLIAMS, J. T., et al. The dependence of the input impedance on feed position of probe and microstrip line-fed patch antennas. IEEE 
Transactions on Antennas and Propagation, 2001, vol. 49, no. 1, p. 45-47. DOI: $10.1109 / 8.910528$

[2] SAMARAS, T., KOULOGLOU, A., SAHALOS, J. N. A note on the impedance variation with feed position of a rectangular microstrip-patch antenna. IEEE Antennas and Propagation Magazine, 2004, vol. 46, no. 2, p. 90-92. DOI: 10.1109/MAP.2004.1305543

[3] HU, Y., JACKSON, D. R., WILLIAMS, J. T., et al. Characterization of the input impedance of the inset-fed rectangular microstrip antenna. IEEE Transactions on Antennas and Propagation, 2008, vol. 56, no. 10, p. 3314-3318. DOI: 10.1109/TAP.2008.929532

[4] ZHANG, X., ZHU, L. Patch antennas with loading of a pair of shorting pins toward flexible impedance matching and low cross polarization. IEEE Transactions on Antennas and Propagation, 2016, vol. 64, no. 4, p. 1226-1233. DOI: 10.1109/TAP.2016.2526079

[5] KANDWAL, A., SHARMA, R., KHAH, S. K. Bandwidth enhancement using Z-shaped defected ground structure for a microstrip antenna. Microwave and Optical Technology Letters, 2013 , vol. 55 , no. 10 , p. $2251-2254$. DOI: $10.1002 / \mathrm{mop} .27836$

[6] KHANDELWAL, M. K., KANAUJIA, B. K., DWARI , S., et al. Bandwidth enhancement and cross-polarization suppression in ultrawide band microstrip antenna with defected ground plane. Microwave and Optical Technology Letters, 2014, vol. 56, no. 9, p. 2141-2146. DOI: 10.1002/mop.28499

[7] GUHA, D., KUMAR, C., PAL, S. Improved cross-polarization characteristics of circular microstrip antenna employing arc shaped defected ground structure (DGS). IEEE Antennas and Wireless Propagation Letters, 2009, vol. 8, p. 367-1369. DOI: 10.1109/LAWP.2009.2039462

[8] KUMAR, C. GUHA, D. Asymmetric geometry of defected ground structure for rectangular microstrip: A new approach to reduce its cross-polarized fields. IEEE Transactions on Antennas and Propagation, 2016, vol. 64, no. 6, p. 2503-2506. DOI: 10.1109/TAP.2016.2537360

[9] PASHA, M. I., KUMAR, C., GUHA, D. Simultaneous compensation of microstrip feed and patch by defected ground structure for reduced cross-polarized radiation. IEEE Transactions on Antennas and Propagation, 2018, vol. 66, no. 12, p. 7348-7352. DOI: 10.1109/TAP.2018.2869252

[10] GHOSH, A., CHAKRABORTY, S., CHATTOPADHYAY, S., et al. Rectangular microstrip antenna with dumbbell shaped defected ground structure for improved cross polarised radiation in wide elevation angle and its theoretical analysis. IET Microwaves, Antennas and Propagation, 2016, vol. 10, p. 68-78. DOI: 10.1049/iet-map.2015.0179

[11] CHATTOPADHYAY, S., BISWAS, M., SIDDIQUI, J. Y., et al. Rectangular microstrips with variable air gap and varying aspect ratio: Improved formulations and experiments. Microwave and Optical Technology Letters, 2009, vol. 51, no. 1, p. 169-173. DOI: 10.1002/mop. 24025

[12] GARG, R., BHARTIA, P., BAHL, I., ITTIPIBOON, A. Microstrip Antenna Design Handbook. Boston - London: Artech House, 2001. ISBN-13: 978-0890065136

[13] HIRAYAMA, H. Equivalent circuit and calculation of its parameters of magnetic-coupled-resonant wireless power transfer In KIM, K. I. (Ed.) Wireless Power Transfer - Principles and Engineering Explorations. InTech, 2012, p. 117-132. ISBN: 978953-307-874-8

\section{About the Authors ...}

Juin ACHARJEE received her B. Tech degree and M. Tech degree in Electronics \& Communication Engineering from the Maulana Abul Kalam Azad University of Technology (MAKAUT), in 2010, and 2013, respectively. She is currently pursuing her Ph.D. from the National Institute of Technology, Durgapur, West Bengal, India. From 2018 she is working as an Assistant Professor in the Department of Electronics \& Communication Engineering, St. Thomas College of Engineering \& Technology, West Bengal, India. Her research interest includes characterization of defective ground structures (DGS) and their applications in performance enhancement of microstrip antenna, and design and analysis of compact UWB antenna.

Amit Kumar SINGH was born in 1994. He received his B. Tech in Electronics \& Communication Engineering (ECE) from NSHM Knowledge Campus Durgapur under MAKAUT formerly known as West Bengal University of Technology (WBUT), in 2016. He is currently pursuing M. Tech from IIT ISM Dhanbad.

Kaushik MANDAL received his B. Sc degree in Physics (H), B. Tech and M. Tech degree in Radio Physics and Electronics from the University of Calcutta, in 2001, 2004 and 2006, respectively. He received his Ph.D. (Tech.) from the University of Kalyani, in July 2014. From 2016 he is working as an Assistant Professor in the Institute of Radio Physics and Electronics, University of Calcutta, West Bengal, India. He has authored or co-authored over 25 internationally refereed journal and conference papers. His current research interests include the characterization and application of DGS, antennas for RF energy harvesting system, SIW integrated microstrip antenna, and performance enhancement of microstrip antenna using frequency selective surface (FSS). Dr. Mandal is an active reviewer of IEEE Transactions on Antennas and Propagation, IEEE Antennas and Propagation Magazine, Progress in Electromagnetics Research (PIER), and AEÜ - International Journal of Electronics and Communications. Dr. Mandal is a senior member of IEEE.

Sujit Kumar MANDAL received B. Sc degree in Physics (Honours) from the University of Calcutta in 2001. He completed B. Tech and M. Tech in Radio Physics \& Electronics from the Institute of Radio Physics \& Electronics, C. U. in the year 2004 and 2006, respectively. He received Ph.D. degree from the National Institute of Technology, Durgapur where he is presently an Assistant Professor in the Department of Electronics and Communication Engineering. His present research area includes application of soft computing techniques in antenna array optimization, time-modulated antenna arrays, microstrip patch antenna, RF energy harvesting and on-chip antenna design. 